\title{
Adaptive Modulation and Coding (AMC) around Building Environment for MS Communication at The Train
}

\author{
Andrita Ceriana Eska \\ Electrical Engineering Department, University of Jember, Indonesia \\ andritacerianaeska@gmail.com
}

\begin{abstract}
This paper focused at communication systems when train moved. The communication propagation was influenced by building environment. The communication condition that used uplink direction. Mobile station was placed inside the train where moved with $500 \mathrm{~km} /$ hour velocity. The analysis was used consists of Doppler effect, atmospheric, and building environment. The variation communication frequency was used consists of $2.6 \mathrm{GHz}, 5 \mathrm{GHz}$, and $10 \mathrm{GHz}$. Diffraction mechanism caused building was used single knife edge method. The result was showed SNR value from the communication frequency variation, distance comparison between LOS and NLOS, alteration adaptive modulation and coding (AMC), and coverage area percentage. Modulation and Coding Scheme (MCS) was used for AMC consists of QPSK, 16 QAM, and 64 QAM. Decreases of SNR value can be occured when communication distance for NLOS condition farther then LOS condition. That distance became increases because was obstructed with high building. Changeable of AMC value was caused propagation condition. The coverage area percentage when communication frequency that was used consists of $2.6 \mathrm{GHz}, 5$ $\mathrm{GHz}$, and $10 \mathrm{GHz}$ was obtained 88.4\%, 88.4\%, and 81.7\%.
\end{abstract}

Keywords: building, AMC, train, single knife edge, QAM.

\section{INTRODUCTION}

The Cellular communication systems can be using millimeter wave. The usage that millimeter wave can be influenced by atmospheric. Some research that used millimeter wave such as influence code rate at communication system of RBS femto cell using $47 \mathrm{GHz}$ frequency [1], $38 \mathrm{GHz}$ and $60 \mathrm{GHz}$ frequency for wireless peer to peer communication where propagation can be occurred by multipath because obstacle by building [2], handoff mechanism using $60 \mathrm{GHz}$ frequency at wireless systems [3], propagation mechanism where handoff condition at 5G mobile communication [4], loss diffraction analysis of NLOS condition used small cell backhaul at millimeter wave [5], propagation model was using communication millimeter wave at $5 \mathrm{G}$ wireless network [6], mobile station determination was using $47 \mathrm{GHz}$ 
frequency [7], bandwidth influence that was caused by multipath around building for mobile communication with $47 \mathrm{GHz}$ frequency [8], and RBS femto cell used $10 \mathrm{GHz}$ frequency that was placed at above pole lamp [9].

NLOS condition at communication systems can be influenced by mechanism diffraction, such as at this research was discussed about $2.4 \mathrm{GHz}$ frequency for mobile communication systems of tree obstacle [10], and diffraction upon building at mobile communication systems was using millimeter wave [11]. Some research about modulation adaptive mechanism was consists of segmentation area strategic for adaptive transmission at fixed cellular communication was using $30 \mathrm{GHz}$ [12].

This research was modeled communication system between base transceiver station and mobile station. The mobile station location was placed inside the train, where the train was moved with velocity of 500 $\mathrm{km} /$ hour. The communication environment was modeled with building environment condition. Adaptive modulation and coding (AMC) process was used for that communication systems.

\section{RELATED WORKS}

The goal of this research was for finding alteration AMC and MCS probability. Some methods those used were such as single knife edge, Adaptive Modulation and Coding (AMC), Modulation and Coding Scheme (MCS). Single knife edge method was used for diffraction analysis, that method was related with some research such as diffraction influence around building used millimeter wave [11], and multipath effect around building environment [8].

\section{ORIGINALITY}

This research focused about communication systems for mobile station that was placed at inside the train. The train of velocity used $500 \mathrm{~km} /$ hour. The originality at this research was showed at usage frequency variation, the relation train velocity with SNR value. Alteration AMC was based on MCS level. That communication propagation that used uplink condition. The communication environment was used building environment. Single knife edge method was used for diffraction mechanism through that building. The analysis was used consists of frequency communication variation, Doppler effect, atmospheric attenuation, building environment, and adaptive modulation and coding (AMC) process. The frequency variation that was used consists of $2.6 \mathrm{GHz}, 5 \mathrm{GHz}$, and $10 \mathrm{GHz}$. Modulation and coding scheme (MCS) variation that was used consists of QPSK, 16 QAM, and 64 QAM [13]. The result showed different communication distance at LOS and NLOS, SNR different based on communication frequency variation, ACM alteration at mobile station communication that base on train, and coverage are percentage from train track. 


\section{SYSTEM DESIGN}

Mobile station can be placed everywhere. This research focused on communication modeled for mobile station of inside the train. The velocity of train moved around $500 \mathrm{~km} /$ hour. The result communication systems that modeled can be seen at Figure 1. That figure was showed communication environment condition available many building. Diffraction mechanism was caused that building modeled used single knife edge diffraction method. The high building variation was used consists of 10 meter, 20 meter, 30 meter, and 40 meter. The high of Base Transceiver Station (BTS) that was used 30 meter. The high of mobile station for inside the train was used 2.5 meter. Train track along as far as $1 \mathrm{~km}$, that mobile station moved as far as $1 \mathrm{~km}$. The frequency variation for communication that was used $2.6 \mathrm{GHz}, 5 \mathrm{GHz}$, and $10 \mathrm{GHz}$. The usage that frequency can be influenced by atmospheric attenuation [14]. The equation for atmospheric attenuation can be seen at equation (1). $\gamma_{0}, \gamma_{n} \gamma_{\infty}$, and $\boldsymbol{A}$ parameter was represented as path length $(\mathrm{km})$, gaseous attenuation, attenuation from dry air $(\mathrm{dB} / \mathrm{km})$. water vapor attenuation $(\mathrm{dB} / \mathrm{km})$, and attenuation path.

$$
A=\gamma r_{o}=\left(\gamma_{0}+\gamma_{w}\right) r_{0} d B
$$

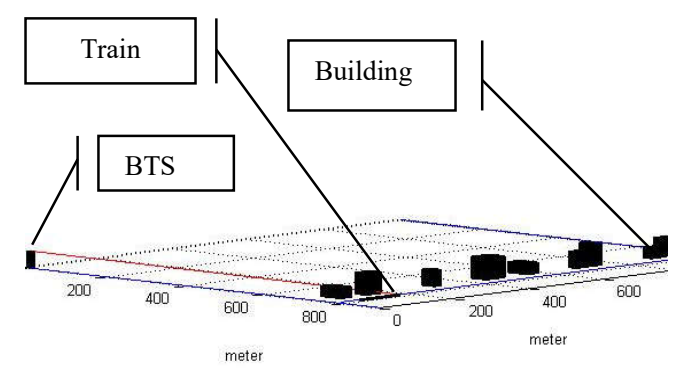

Figure 1. The communication environment model

Single knife edge method was used for diffraction mechanism, can be seen at Figure 2 [15]. Single knife edge method equation can be seen at equation (2). $v, \lambda, h, d_{1}$ and $d_{2}$ parameter was represented as Fresnel Kirchoff, wave long $(\mathrm{m})$, diffraction node high (meter), transmitter distance through diffraction node, and receiver distance through diffraction node $(\mathrm{m})$. 


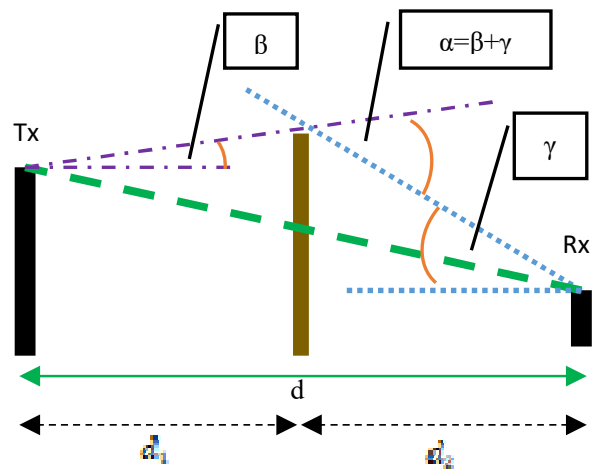

Figure 2. Difraksi knife edge

$$
v=h \sqrt{\frac{d\left(d_{1}+d_{2}\right)}{\lambda d_{1} d_{2}}}=\alpha \sqrt{\frac{2 d_{1} d_{3}}{\lambda\left(d_{1}+d_{2}\right)}}
$$

The margin link value can be determined at equation (3). EIRP, $\mathrm{G}_{\mathrm{rx}}$, $\mathrm{L}_{\text {path }}$ and $\mathrm{TH}_{\mathrm{rx}}$ parameters are represented by effective isotropic radiated power, receive gain $(\mathrm{dB})$, path loss total, and receiver threshold or minimum received signal level (dBw or $\mathrm{dBm})$ [15]. Threshold ACM based on modulation variation. The modulation variation that was used consists of QPSK, 16 QAM, and 64 QAM. Code rate QPSK that was used consist of 1/8, $1 / 5,1 / 4,1 / 3,1 / 2,2 / 3,3 / 4$, and $4 / 5$. Code rate 16 QAM that was used consist of $1 / 2,2 / 3,3 / 4$, and $4 / 5$. Code rate for 64 QAM modulation that was used consist of $2 / 3,3 / 4$, and $4 / 5$ [16].

$$
\text { Link margin }=E I R P-L_{\text {path }}+G_{r x}-T H_{r x}
$$

The path loss value (L) can be seen at equation (4). $G_{T}, G_{R}, d$, and $\lambda$ parameter are represented by gain transmitter, gain receiver, communication distance, and wave length [15]. Power transmitter for mobile station was used $20 \mathrm{dBm}$.

$$
L=G_{T} \cdot G_{R} \cdot\left(\frac{\lambda}{4 \pi d}\right)
$$

The noise of communication system can be seen at equation (5), where $\mathrm{K}, \mathrm{B}, T_{\sigma}$, and $\mathrm{F}$ are represented by Boltzman constant, bandwidth, standard noise temperature, and noise figure [15]. Bandwidth channel was used 5 $\mathrm{MHz}$, so the bandwidth for thermal noise that was used 25 resource block of Long Term Evolution (LTE) and $180 \mathrm{kHz}$ for every resource block. Noise figure (F) value can be seen at equation (6) and SNR value can be seen at equation (7).

$$
\begin{aligned}
& N=k T_{0} B F \\
& F=\left(1+\frac{T_{\varepsilon}}{T_{0}}\right)
\end{aligned}
$$




$$
S N R=\frac{S}{N}
$$

$T_{o}$ and $T_{*}$ parameter was represented by standard noise temperature and noise temperature at receive. $F$ value that was used $5 \mathrm{~dB}$. Signal to noise (SNR) be seen at equation (7). S and $\mathrm{N}$ value are represented by signal and noise [15]. Adaptive Modultion and Coding was adapting MCS level from alteration of SNR value. Some MCS level was used such as QPSK, 16 QAM, and 64 QAM.

\section{EXPERIMENT AND ANALYSIS}

The communication propagation between BTS and MS was modeled uplink condition from mobile station of inside the train. The communication environment was modeled many building. The result was used consists of SNR value from frequency variation, distance comparison between LOS and NLOS, adaptive modulation and coding (AMC), building environment, Doppler effect, and coverage area percentage. The communication frequency variation that used such as $2.6 \mathrm{GHz}, 5 \mathrm{GHz}$, and $10 \mathrm{GHz}$. That frequency was influenced by atmospheric attenuation. Adaptive modulating and coding was used consists of QPSK, 16 QAM, and 64 QAM modulation. The communication systems for NLOS condition was influenced by high building. Because of that was occurred diffraction mechanism,

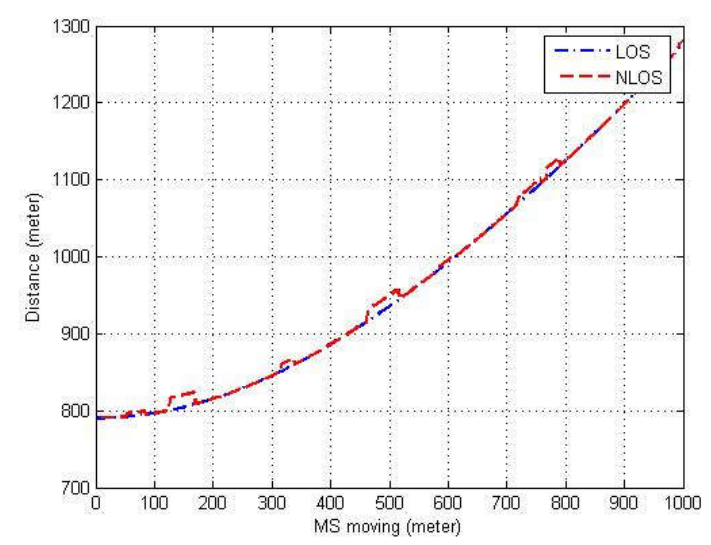

Figure 3. LOS and NLOS distance

Figure 3 was showed comparison for communication distance between LOS and NLOS. Some data was consists of when train moved around 100 meter was obtained distance for 796.8 meter NLOS and 796.8 meter LOS, when train moved 337 meter was obtained distance for 868.2 meter NLOS and 859.3 meter LOS, when train moved 800 meter was obtained distance for 1124.7 meter NLOS and 1124.7 meter LOS. NLOS condition was caused by high building.

Figure 4 was showed variation of communication frequency consists of $2.6 \mathrm{GHz}, 5 \mathrm{GHz}$, and $10 \mathrm{GHz}$. Alteration for adaptive modulation and coding can be observed at Figure 5. That ACM was showed 1 until 15, that was represented of QPSK code rate $1 / 8$, QPSK code rate $1 / 5$, QPSK code rate $1 / 4$, 
QPSK code rate $1 / 3$, QPSK code rate $1 / 2$, QPSK code rate $2 / 3$, QPSK code rate $3 / 4$, QPSK code rate $4 / 5,16$ QAM code rate $1 / 2,16$ QAM code rate $2 / 3,16$ QAM code rate 3/4, 16 QAM code rate 4/5, 64 QAM code rate 2/3, 64 QAM code rate $3 / 4$, and $64 \mathrm{QAM}$ code rate $4 / 5$. SNR value for $2.6 \mathrm{GHz}$ frequency at 100 meter point without Doppler effect was obtained $25.579268 \mathrm{~dB}$, and when used Doppler effect was obtained $25.579264 \mathrm{~dB}$, so modulation for ACM was used $64 \mathrm{QAM}$ with code rate 4/5. SNR value for $10 \mathrm{GHz}$ frequency without Doppler effect was obtained $13.878735 \mathrm{~dB}$, and when used Doppler effect was obtained $13.878731 \mathrm{~dB}$, so modulation for ACM was used 16 QAM with code rate $4 / 5$.

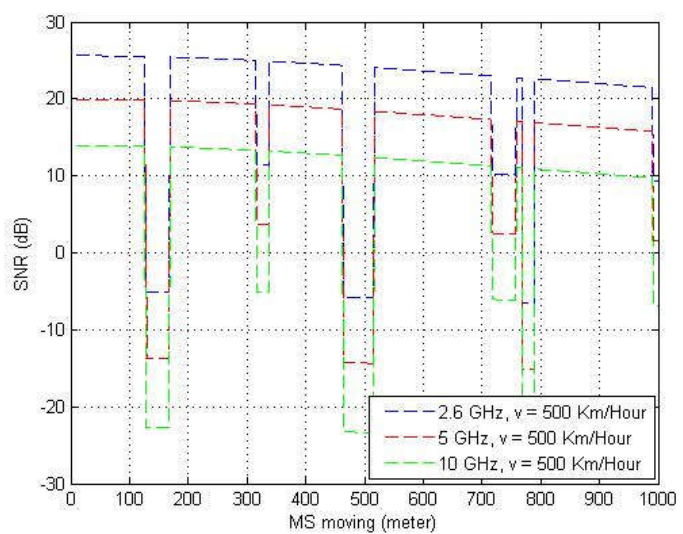

Figure 4. SNR value from communication result

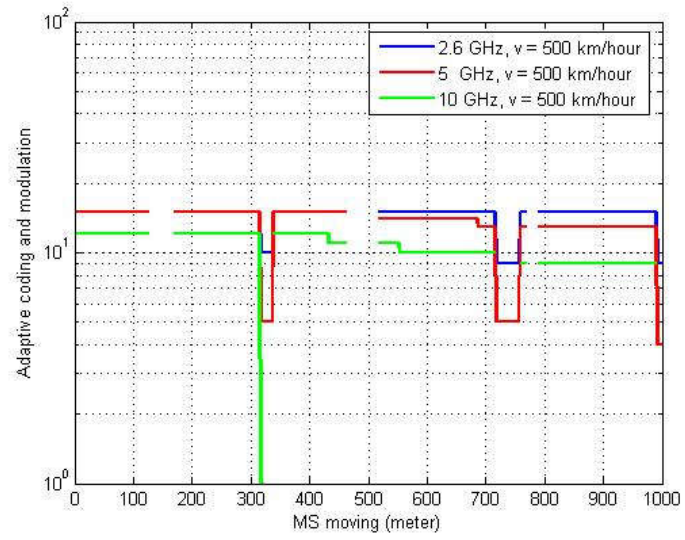

Figure 5. Adaptive modulation and coding mobile station 


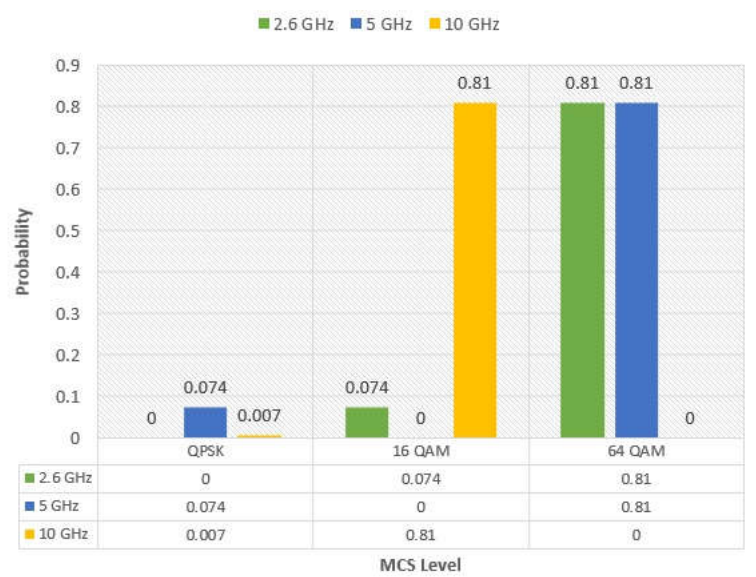

Figure 6. MCS probability

SNR value for $2.6 \mathrm{GHz}$ frequency at 337 meter point without Doppler effect was obtained $11.365737 \mathrm{~dB}$, and when used Doppler effect was obtained $11.3657318 \mathrm{~dB}$, so modulation for ACM was used 16 QAM with code rate $2 / 3$. SNR value for $5 \mathrm{GHz}$ frequency without Doppler effect was obtained $3.700477 \mathrm{~dB}$, and when used Doppler effect was obtained $3.700471 \mathrm{~dB}$, so modulation for ACM was used QPSK with code rate $1 / 2$. SNR value for $10 \mathrm{GHz}$ frequency without Doppler effect was obtained $-5.125650 \mathrm{~dB}$, and when used Doppler effect was obtained $-5.125656 \mathrm{~dB}$. That SNR value was used under threshold of ACM, so that point without communication coverage. That decreases for SNR value was caused obstacle by building, atmospheric attenuation, and Doppler effect.

SNR value for $2.6 \mathrm{GHz}$ frequency at 800 meter point without Doppler effect was obtained $22.540201 \mathrm{~dB}$, and when used Doppler effect was obtained $22.540197 \mathrm{~dB}$, so modulation for ACM was used 64 QAM with code rate $4 / 5$. SNR value for $5 \mathrm{GHz}$ frequency without Doppler effect was obtained $16.860268 \mathrm{~dB}$, and when used Doppler effect was obtained $16.860264 \mathrm{~dB}$, so modulation for ACM was used 64 QAM with code rate 2/3. SNR value for 10 $\mathrm{GHz}$ frequency without Doppler effect was obtained $10.839668 \mathrm{~dB}$, and when used Doppler effect was obtained $10.839664 \mathrm{~dB}$, so modulation for ACM was used 16 QAM with code rate $1 / 2$. The alteration for ACM value at $5 \mathrm{GHz}$ frequency was consists of MS was moving 100 meter, 337 meter, and 800 meter, so was obtained 64 QAM code rate 4/5, QPSK code rate $1 / 2$, and 64 QAM code rate $2 / 3$.

Figure 6 was showed probability result of MCS level. That probability at modulation and coding scheme (MCS) when used $2.6 \mathrm{GHz}$ frequency of probability at MSC for QPSK, 16 QAM, and 64 QAM was obtained 0, 0.074, and 0.81 . That QPSK was found 0 value because SNR communication still above threshold QPSK. When used $5 \mathrm{GHz}$ frequency of probability at MCS for QPSK, 16 QAM, and 64 QAM was obtained $0.007,0$, and 0.81 . That 16 QAM was found 0 value because SNR communication still above threshold 16 QAM, and another under 16 QAM threshold that was caused building obstacle. The coverage area percentage of communication result when used $2.6 \mathrm{GHz}$ 
frequency was obtained $100 \%$, when used $5 \mathrm{GHz}$ frequency was obtained $100 \%$, and when used $10 \mathrm{GHz}$ frequency was obtained $87 \%$.

SNR value was showed decreases because building obstacle. Some data was consists of mobile station moved 337 meter of $2.6 \mathrm{GHz}$ frequency for 859.3 meter LOS was obtained $11.365737 \mathrm{~dB}$ and 868.2 meter NLOS was obtained $11.365731 \mathrm{~dB}$. That distance was showed increases for communication distance, whereas it decreases for SNR value.

The coverage area percentage based on communication points at track. Every that communication point influenced by communication frequency, adaptive modulation and coding, Doppler effect, atmospheric attenuation, and building environment. The result was showed increases for frequency, whereas it decreases of coverage area percentage. Some data for coverage area percentage was consists of $2.6 \mathrm{GHz}, 5 \mathrm{GHz}$, and $10 \mathrm{GHz}$ frequency, was obtained $100 \%, 100 \%$, and $87 \%$ percentage.

\section{CONCLUSION}

Adaptive modulation and coding was used for mobile station communication, that mobile station was placed inside train. That train moved $500 \mathrm{~km} /$ hour velocity. The coverage area percentage was resulted consists of $2.6 \mathrm{GHz}, 5 \mathrm{GHz}$, and $10 \mathrm{GHz}$, was obtained 100\%, 100\%, and 87\%. SNR value for that communication was influenced by atmospheric attenuation, Doppler effect, and building variation. The distance propagation was showed increases for communication distance, whereas it decreases for SNR value. The signal to noise value was influenced for alteration of ACM around QPSK, 16 QAM, and 64 QAM.

\section{REFERENCES}

[1] A.C. Eska, Pengaruh Code Rate untuk Komunikasi RBS Femtocell Frekuensi 47 GHz pada Tiang Lampu Jalan, Jurnal Infotel, Vol.9, No.4, 2017.

[2] T.S. Rappaport, E.B. Dor, J.N. Murdock, and Y. Qiao, 38 GHz and 60 GHz Angle-dependent Propagation for Cellular \& Peer-to-Peer Wireless Communications, IEEE ICC Wireless Communications Symposium, 2012.

[3] B.V. Quang, R.V. Prasad, and I. Niemegeers, A Survey on Handoffs Lessons for $60 \mathrm{GHz}$ Based Wireless Systems, IEEE Communications Surveys \& Tutorial, Vol.14, No.1, 2012.

[4] T.S. Rappaport, G.R. MacCartney, S. Sun, H. Yan, and S. Deng, SmallScale, Local Area, and Transitional Millimeter Wave Propagation for 5G Communications, IEEE Transactions on Antennas and Propagation, Vol. 65, No.12, 2017.

[5] B. Malila, O. Falowo, and N. Ventura, Millimeter Wave Small Cell Backhaul : An Analysis of diffraction loss in NLOS links in Urban Canyons, IEEE, 2015.

[6] T.S. Rappaport, Y. Xing, G.R. MacCartney, A.F. Molisch, and E. Mellios, J. Zhang, Overview of Millimeter Wave Communications for Fifth- 
Generation (5G) Wireless Networks-With a Focus on Propagaiton Models, IEEE Transactions on Antennas and Propagation, Vol. 65, No.12, 2017.

[7] A.C. Eska, Determination of MS Location through Building Using AoA Method of Frequency 47 GHz, IJITEE, Vol.1, No.3, 2017.

[8] A.C. Eska, Multipath Effects in Building Environment Toward Bandwidth Enhancement for Mobile Communication of $47 \mathrm{GHz}$ Frequency, Jurnal Infotel, Vol. 10, No.1, 2018.

[9] A.C. Eska, Propagasi Komunikasi Radio Base Station Femtocell pada Tiang Lampu Jalan Frekuensi 10 GHz, Jurnal Infotel, Vol.9, No.4, 2017.

[10] A.C. Eska, Komunikasi Bergerak Frekuensi 2.3 GHz Melewati Pepohonan Menggunakan Metode Giovanelli Knife Edge, Jurnal Infotel, Vol. 8, No.1, 2016.

[11] A.C. Eska, and G. Hendrantoro, Preliminary study on the effect of building-induced diffraction upon millimeter wave mobile communications systems with macrodiversity, TSSA, 2012.

[12] Suwadi, G. Hendrantoro, and Wirawan. An Area Segmentation Strategy for Adaptive Transmission to Achieve Near-Uniform High Quality Coverage in $30 \mathrm{GHz}$ Fixed Wireless Cellular Systems in Tropical Regions, WSEAS Transactions on Communication, Vol.10, No.8, 2011.

[13] 3GPP, 3rd Generation Partnership Project; Technical Specification Group Radio Access Network; Physical layer aspects of UTRA High Speed Downlink Packet Access, 3GPP, 2001.

[14] ITU, ITU-R Radio Communication Sector of ITU (Attenuation by atmospheric gases), Geneva : Electronic Publication, 2013.

[15] J.S. Seybold, Introduction to RF Propagation, New Jersey: John Wiley\&Sons, 2005.

[16] 0. Werther, LTE System Specifications and their Impact on RF \& Base Band Circuits, Rohde \& Schwarz, 2013. 